Journal Club

Editor's Note: These short, critical reviews of recent papers in the Journal, written exclusively by graduate students or postdoctoral fellows, are intended to summarize the important findings of the paper and provide additional insight and commentary. For more information on the format and purpose of the Journal Club, please see http://www.jneurosci.org/misc/ifa_features.shtml.

\title{
The Role of the Occipital Cortex in Resolving Perceptual Ambiguity
}

\author{
-Pablo R. Grassi, ${ }^{1,2,3,4 *}$ Georg Schauer, ${ }^{1,2,3,4 *}$ and Abhilash Dwarakanath ${ }^{4}$ \\ ${ }^{1}$ Centre for Integrative Neuroscience, ${ }^{2}$ Department of Psychology, and ${ }^{3}$ Graduate Training Centre of Neuroscience, 72076 Tübingen, Germany, and \\ ${ }^{4}$ Max Planck Institute for Biological Cybernetics, 72076 Tübingen, Germany \\ Review of de Jong et al.
}

During observation of an ambiguous stimulus, our perception alternates spontaneously between mutually exclusive interpretations, although the physical stimulus remains constant. Although the term "ambiguous stimulus" often evokes thoughts of a single image that can be interpreted in two ways (e.g., the duck/rabbit image), ambiguous stimuli can also be produced by presenting two different images individually to the two eyes. In that case, rather than seeing a mixture of the two, our perception switches between the images. This phenomenon is known as binocular rivalry and has long been used to study perceptual awareness, because of the dissociation of consciousness from sensory processing.

Previous theoretical models have suggested that such cases of bistability arise from a form of reciprocal inhibition between sensory neural populations competing for awareness. However, studies in the past decade have questioned this hypothesis and have stressed the involvement of higher cognitive mechanisms within the frontoparietal network in solving perceptual ambiguity (Sterzer et al., 2009). Although the debate about the use of different mechanisms along the visual hierarchy in switching percepts is now more balanced, the

\footnotetext{
Received July 28, 2016; revised Aug. 27, 2016; accepted Aug. 30, 2016. The authors declare no competing financial interests.

*P.R.G. and G.S. contributed equally to this work.

Correspondence should be addressed to Pablo R. Grassi, Vision and Cognition Laboratory, Centre for Integrative Neuroscience, University of Tübingen, Otrfried-Müller-Strasse 25, 72076 Tübingen, Germany. E-mail: pablo.grassi@cin.uni-tuebingen.de.

DOI:10.1523/JNEUROSCI.2402-16.2016

Copyright $\odot 2016$ the authors $\quad 0270-6474 / 16 / 3610508-02 \$ 15.00 / 0$
}

mechanisms involved in the initiation of the alternations are yet to be understood. It is still unclear where along the visuocognitive hierarchy the endogenous switches are initiated, because the extent to which sensory occipital areas and the frontoparietal areas are involved remains unclear.

Following this line of research, a recent study (de Jong et al., 2016) made an important attempt to answer the question of where perceptual ambiguity is being resolved, by using electrocorticography to detect transient response patterns in the occipital lobe occurring during spontaneous perceptual changes [endogenously initiated perceptual switches that happen while viewing a different image with each eye or while viewing a bistable structure-frommotion display (SFM)], as well as during stimulus-induced perceptual changes (exogenously initiated perceptual switches that occur together with changes in the stimuli that mimic spontaneous perceptual changes). The binocular rivalry stimulus consisted of two images (face and house) presented to the two eyes, while the SFM stimulus was composed of horizontally moving dots that give rise to the illusion of a rotating $3 \mathrm{D}$ globe with ambiguous rotation direction. For comparison with the ambiguous stimuli, they used unambiguous stimuli that elicited changes in perception that are nearly indistinguishable from those elicited by the ambiguous stimuli.

Stimuli were presented in two sessions consisting of four 2 min blocks of stimulation interleaved with $10 \mathrm{~s}$ fixation. Participants were asked to report their current percept (i.e., face/house and left/right motion) by pressing and holding one of two buttons. To investigate transient responses, the authors centered the epochs in time to the moment of the subjective reports $(-2$ to $+2 \mathrm{~s})$. They focused their analysis on the following two frequency bands: 3-30 (theta, alpha, and beta bands); and 50$130 \mathrm{~Hz}$ (gamma band). Given the variation in the time period between actual perceptual switches and button presses, they performed an additional analysis that was insensitive to this reaction time jitter by calculating the areas delimited by the report-locked changes within a time window of -1500 to $+500 \mathrm{~ms}$ relative to button press.

The analysis of the power spectra aligned to button presses revealed a broadband decrease in the power of the low frequencies (3-30 Hz) together with a broadband increase of high frequencies $(50-130 \mathrm{~Hz})$ before the report, regardless of stimulus (binocular rivalry or SFM) and, most importantly, of experimental condition (ambiguous/unambiguous stimulation). In the analysis that was insensitive to the reaction time jitter, they examined the decrease in low-frequency power and the increase in high-frequency power by looking at the area under the curve below and above the normalized power, respectively. Results from this analysis yielded a similar modulation pattern, showing a decrease in lowfrequency power (in binocular rivalry and SFM) and an increase in high-frequency power (in SFM only).

de Jong et al. (2016) interpret the recorded transient response patterns as evidence that the initiation of spontaneous 
perceptual switches occurs within occipital cortex rather than elsewhere. Specifically, they reason that bistability arises from feedforward and feedback interactions within early visual neural networks. Although the presented evidence is clear, the fact that it is limited to occipital cortex does not allow closure of the debate on where perceptual reversals are initiated. Their suggestion is largely based on the observation that transient activity is present in the occipital cortex before the perceptual switch report. However, similar transient activity preceding the switch report has also been observed in the parietal cortex for a bistable stimulus and binocular rivalry (Britz et al., 2009; Britz and Pitts, 2011).

de Jong et al. (2016) reason that only the initiation of perceptual switches within the occipital cortex would explain transient activations around the timing of a perceptual change. Yet, the presence of such activity in higher brain areas indicates another possibility, as follows: even if the occipital cortex maintains a percept through inputs from higher cortical regions, one would expect transient activations concurrent with these inputs. A buildup of activity signaling an oncoming perceptual switch could translate into transient occipital activity without the causal involvement of that region.

Support for this view comes from TMS studies on parietal cortex, showing that inhibitory stimulation changes the rate of perceptual reversals, which in turn indicates a causal role of higher cortical regions in bringing them about (Carmel et al., 2010; Kanai et al., 2010; Zaretskaya et al., 2010). Conversely, the conclusion of de Jong et al. (2016) is supported by recent fMRI studies that question the involvement of higher cortical regions in resolving perceptual ambiguity, by showing that binocular rivalry can occur in the absence of frontoparietal activity (Brascamp et al., 2015), which might instead be related to introspection, awareness, and report (Frässle et al., 2014).

The rationale behind many previous studies on bistable perception was to specifically compare responses to ambiguous stimuli with those related to unambiguous ones. Thus, many studies focused their analyses on the contrast between ambiguous and unambiguous conditions. In line with this reasoning, the results presented by de Jong et al. (2016) could be seen as evidence that bistability is not resolved in the occipital cortex, because occipital activity during bistability does not seem to differ from that of normal perception. Their results are consistent with the idea that the occipital cortex receives inputs of already resolved rivalry and then uses similar processing mecha- nisms for both. This alternative interpretation is in accordance with fMRI studies that, while they revealed switch-related modulation of the occipital cortex with both bistable and regular stimulation, showed that frontoparietal activity was specifically associated with endogenously induced perceptual switches (for review, see Sterzer et al., 2009). Additional evidence from electrophysiology in the form of single-neuron measurements also showed percept-driven modulations in the macaque prefrontal cortex (Panagiotaropoulos et al., 2012). An analysis of their data from frontoparietal electrodes might shed additional light on this issue.

Another interesting interpretation that de Jong et al. (2016) propose concerns the role of neural oscillations. The authors relate the increase in high-frequency power with local, rapidly occurring processes and the decrease in low-frequency power with global, slower processes (Donner and Siegel, 2011). They propose a dissociation, whereby high-frequency modulation is reminiscent of endogenous perceptual switch initiation while low-frequency oscillations carry change-related activity across visual areas to aid percept maintenance. This interpretation is consistent with the fact that the high-level activity they report was more spatially confined and peaked earlier than low-frequency modulations (de Jong et al., 2016, their Figs. 5, 6).

While this conclusion explains their data, their results are also compatible with conclusions from a recent study (van Kerkoerle et al., 2014) using V1 and V4 macaque recordings, which relate low- and high-frequency oscillations to feedback and feedforward processing, respectively. This is yet a further indication that the transient activity observed by de Jong et al. (2016) may show a dynamic interplay between occipital cortex and other cortical regions rather than demonstrate a causal role of occipital cortex in initiating perceptual reversals. Importantly, as de Jong et al. (2016) also point out, their results do not support a mere bottom-up feedforward process, but also indicate feedback processing.

Taking all these considerations together, a transient low-frequency decrease before perceptual switches could be a signature of feedback signals from higher extrastriate areas within the occipital lobe (e.g., V4, MT+) or higher frontoparietal regions. Indeed, transient activity during spontaneous switches appears to be smaller and wider than that during real switches (de Jong et al., 2016, their Fig. 4). This might show a gradual buildup of activity from feedback signals. In contrast, high-level modulation appeared in feature-selective areas (e.g., in
MT+), suggesting a perception-selective processing of information in a feedforward manner.

In summary, de Jong et al. (2016) make a compelling case for the causal role of the occipital cortex during perceptual reversals. Their use of human intracranial data is novel and builds a bridge between previous human and monkey studies on bistability. However, although de Jong et al. (2016) provide a methodologically persuasive contribution in putting the occipital cortex back in the spotlight, the nature of the transient activity they observed is still to be understood.

\section{References}

Brascamp J, Blake R, Knapen T (2015) Negligible fronto-parietal BOLD activity accompanying unreportable switches in bistable perception. Nat Neurosci 18:1672-1678. CrossRef Medline

Britz J, Pitts MA (2011) Perceptual reversals during binocular rivalry: ERP components and their concomitant source differences. Psychophysiology 48:1490-1499. CrossRef Medline

Britz J, Landis T, Michel CM (2009) Right parietal brain activity precedes perceptual alternation of bistable stimuli. Cereb Cortex 19: 55-65. CrossRef Medline

Carmel D, Walsh V, Lavie N, Rees G (2010) Right parietal TMS shortens dominance durations in binocular rivalry. Curr Biol 20:R799R800. CrossRef Medline

de Jong MC, Hendriks RJ, Vansteensel MJ, Raemaekers M, Verstraten FA, Ramsey NF, Erkelens CJ, Leijten FS, van Ee R (2016) Intracranial recordings of occipital cortex responses to illusory visual events. J Neurosci 36:6297-6311. CrossRef Medline

Donner TH, Siegel M (2011) A framework for local cortical oscillation patterns. Trends Cogn Sci 15:191-199. CrossRef Medline

Frässle S, Sommer J, Jansen A, Naber M, Einhäuser W (2014) Binocular rivalry: frontal activity relates to introspection and action but not to perception. J Neurosci 34:1738-1747. CrossRef Medline

Kanai R, Bahrami B, Rees G (2010) Human parietal cortex structure predicts individual differences in perceptual rivalry. Curr Biol 20: 1626-1630. CrossRef Medline

Panagiotaropoulos TI, Deco G, Kapoor V, Logothetis NK (2012) Neuronal discharges and gamma oscillations explicitly reflect visual consciousness in the lateral prefrontal cortex. Neuron 74:924-935. CrossRef Medline

Sterzer P, Kleinschmidt A, Rees G (2009) The neural bases of multistable perception. Trends Cogn Sci 13:310-318. CrossRef Medline

van Kerkoerle T, Self MW, Dagnino B, Gariel-Mathis MA, Poort J, van der TogtC, Roelfsema PR (2014) Alpha and gamma oscillations characterize feedback and feedforward processing in monkey visual cortex. Proc Natl Acad Sci USA 111:1433214341. CrossRef Medline

Zaretskaya N, Thielscher A, Logothetis NK, Bartels A (2010) Disrupting parietal function prolongs dominance durations in binocular rivalry. Curr Biol 20:2106-2111. CrossRef Medline 